\title{
DESEMPENHO AGRONÔMICO DE CULTIVARES DE ALFACE PARA AS CONDIÇÕES EDAFOCLIMÁTICAS DA REGIÃO DE ALEGRE - ES
}

\author{
CRUZ, Tatiane Paulino da ${ }^{1}$ \\ JUNGER, Leonardo Alvarez ${ }^{2}$ \\ RABELLO, Lilian Katiany Castello ${ }^{3}$ \\ SILVA, Lilianne Gomes da ${ }^{4}$ \\ PASSOS, Renato Ribeiro ${ }^{5}$
}

RESUMO: Dentre as hortaliças consumidas no Brasil, a alface se destaca pela sua importância econômica e produtiva. O objetivo do presente estudo foi caracterizar o desempenho agronômico de oito cultivares de alface para as condições edafoclimáticas da região de Alegre - ES. O delineamento experimental utilizado foi o bloco casualizado, com três repetições, sendo os tratamentos constituídos por oito cultivares de alface: Crespa Repolhuda, Maravilha de Verão, Mimosa Saladbow, Lívia, Americana, Elba, Aurélia e Vitória de Santo Antão. Foram avaliadas as seguintes características agronômicas: massa fresca das folhas, massa seca das folhas, massa fresca do caule, comprimento do caule e número de folhas por planta. As cultivares de alface avaliadas apresentaram valores de comprimento de caule adequados para comercialização (inferior a 6,0 cm), indicando ausência de pendoamento precoce nas mesmas. As cultivares Vitória de Santa Antão, Crespa Repolhuda, Maravilha de Verão, Lívia Americana, Elba e Aurélia foram as mais produtivas com peso de massa fresca variando de 210,0 a 257,6 $\mathrm{g} \mathrm{planta}^{-1}$. A cultivar Mimosa SaladBow foi a única que apresentou peso de massa fresca fora dos padrões comerciais recomendados (inferior a $200 \mathrm{~g}$ planta $^{-1}$ ).

Palavras chave: Lactuca sativa L. Cultivares. Produção.

\section{AGRONOMIC PERFORMANCE OF LETTUCE IN ALEGRE-ES ENVIRONMENTAL CONDITIONS}

SUMMARY - Among the vegetables consumed in Brazil, lettuce stands out for its economic and productive importance. The purpose of this study was to characterize the agronomic performance of eight varieties of lettuce under soil and climatic condition present in Alegre region - ES. The experimental design was block randomized, with three replications, and treatments consisting of eight varieties of lettuce, Crespa Repolhuda, Maravilha de Verão, Mimosa Saladbow, Lívia, Americana, Elba, Aurélia and Vitória de Santo Antão. The lettuce plants were evaluated for agronomic traits: mass of fresh leaves, dry mass of leaves, stem fresh weight, stem length and number of leaves per plant. The lettuce showed stem length suitable for marketing (less than $6.0 \mathrm{~cm}$ ), indicating the absence of early bolting in them. Cultivars Vitoria de Santo Antao, Crespa Repolhuda, Maravilha de Verão, Lívia, Americana, Elba and Aurélia showed the largest values of fresh weight, which ranged from 210.0 to $257.6 \mathrm{~g} \mathrm{plant}^{-1}$. Cultivar Mimosa SaladBow was the only variety that presented weight of fresh out of recommended trade patterns (less than $200 \mathrm{~g}$ plant $\left.^{-1}\right)$.

Keywords: Lactuca sativa L.. Cultivars. Production.

\section{INTRODUÇÃO}

Dentre as hortaliças consumidas no Brasil, a alface, Lactuca sativa L., encontra-se em destaque, devido sua importância econômica e produtiva. Essa olerícola é tradicionalmente cultivada por agricultores familiares, sendo um fator significativo de agregação do homem do campo ( OLIVEIRA et al.

\footnotetext{
${ }^{1}$ Engenheira Agrônoma. Mestrando em Produção Vegetal pela Universidade Federal do Espírito Santo

${ }^{2}$ Engenheiro Agrônomo.

${ }^{3}$ Engenheira Agrônoma. Doutoranda em Produção Vegetal pela Universidade Federal do Espírito Santo

${ }^{4}$ Engenheira Florestal. Doutoranda em Produção Vegetal pela Universidade Federal do Espírito Santo

${ }^{5}$ Professor de Solos do Departamento de Produção Vegetal. Área Solos
} 
2007). Os estados de São Paulo e Minas Gerais são os maiores produtores de alface do país, sendo que o Espírito Santo nos anos de 2008 e 2009 obteve produções, respectivamente, de 1.128 .925 e $983.036 \mathrm{~kg}$ (CEASA-ES 2010).

Tem-se observado a variação do desempenho de diferentes cultivares de alface em diversas regiões brasileiras, onde cada uma expressa de forma distinta o seu potencial genético de acordo com as diferentes condições ambientais, principalmente a temperatura, devido sua baixa capacidade de adaptação, afetando diretamente o desenvolvimento das folhas, formação da cabeça e consequentemente comprometendo a produção (ANDREANI; MARTINS, 2002; SILVA et al. 2000).

De acordo com Figueiredo et al. (2004), a cultura da alface conta com poucas pesquisas para avaliar as cultivares que melhor se adaptam em determinados locais e épocas de plantio, ao contrário do que se observa em outras culturas como a batata, o milho e o feijão. Essa carência de pesquisas leva produtores a utilizarem cultivares recomendadas pelas empresas produtoras de sementes, as quais, no entanto, podem não se adaptarem a uma faixa ampla de ambientes.

Considerando a atual exigência com o consumo de alimentos saudáveis e de melhor qualidade, faz-se necessária a obtenção de cultivares específicas para determinadas regiões. Com isso, objetivou-se com o presente estudo caracterizar o desempenho agronômico de oito cultivares de alface para as condições edafoclimáticas da região de Alegre - ES.

\section{MATERIAIS E MÉTODOS}

O experimento foi conduzido em condições de campo na propriedade Alegre situada no município de Alegre - ES com coordenadas geográficas de $20^{\circ} 45^{\prime} \mathrm{S}, 41^{\circ} 29^{\prime} \mathrm{W}$ e altitude de $150 \mathrm{~m}$.

O clima predominante no município de Alegre - ES é o tropical úmido e os dados climáticos de temperatura média da região foram coletados durante o período de avaliação (06/05/2011 a 15/06/2011), a partir dos registros da estação meteorológica do Centro de Ciências Agrárias da Universidade Federal do Espírito Santo (CCA-UFES), o qual se pode observar média de $19,7^{\circ} \mathrm{C}$, o que indica uma temperatura aceitável para o cultivo da alface, uma vez que a faixa ótima de temperatura para obtenção de máximo rendimento encontra-se entre $12^{\circ} \mathrm{C}$ e $22^{\circ} \mathrm{C}$ (YURI, 2005; VIGGIANO, 1990; MOTA et al., 2003) .

O delineamento experimental utilizado foi em blocos casualizado (DBC), com três repetições e três plantas por tratamento, constituído por oito cultivares de alface: Crespa Repolhuda (Grupo: americana), Maravilha de Verão (Grupo: repolhuda-manteiga), Mimosa SaladBow (Grupo: solta crespa), Lívia (Grupo: solta lisa), Americana (Grupo: americana), Elba (Grupo: solta crespa), Aurélia (Grupo: repolhuda-manteiga) e Vitória de Santo Antão (Grupo: repolhuda-manteiga).

A semeadura das cultivares de alface foi efetuada em bandejas de poliestireno expandido contendo 200 células, preenchidas com substrato comercial Plantmax ${ }^{\circledR}$, sob ambiente protegido. As mudas foram transplantadas ao atingirem quatro pares de folhas definitivas.

A análise química do solo foi realizada no Laboratório de Análises de Fertilizantes, Águas, Minérios, Resíduos, Solos e Plantas do CCA-UFES, (LAFARSOL), localizado no Núcleo de Estudos e Difusão de Tecnologia em Floresta, Recursos hídricos e Agricultura Sustentável (NEDTEC) em Jerônimo Monteiro - ES, antes do preparo inicial do solo e apresentou os seguintes resultados: $\mathrm{pH}=4,8 ; \mathrm{P}=2,4 \mathrm{mg}$ $\mathrm{dm}^{-3} ; \mathrm{K}=45 \mathrm{mg} \mathrm{dm}{ }^{-3} ; \mathrm{Ca}=0,31 \mathrm{cmol}_{\mathrm{c}} \mathrm{dm}^{-3} ; \mathrm{Mg}=0,12 \mathrm{cmol}_{\mathrm{c}} \mathrm{dm}^{-3} ; \mathrm{H}+\mathrm{Al}=6,8 \mathrm{cmol}_{\mathrm{c}} \mathrm{dm}^{-3} ; \mathrm{V}=17 \% ; \mathrm{e}$ CTC $=7,3 \mathrm{cmol}_{\mathrm{c}} \mathrm{dm}^{-3} ; \mathrm{S} . \mathrm{B}=0,5 \mathrm{cmol}_{\mathrm{c}} \mathrm{dm}^{-3}$.

Os canteiros, onde foram transplantadas as mudas de alface, tinha uma área útil de 2,5 m², com espaçamento de plantas de $0,25 \mathrm{~m}$ x 0,25 m, totalizando 40 plantas por canteiro. A correção da acidez do 
solo dos canteiros foi feita de acordo com a necessidade apresentada na análise de solo com aplicação de calcário, 30 dias antes do transplantio segundo o Manual de Recomendação de Calagem e Adubação para o Estado do Espírito Santo $5^{\circ}$ Aproximação, na dose de 4,8 $\mathrm{t} \mathrm{ha}^{-1}$, sendo irrigado durante este período.

$\mathrm{O}$ cálculo de adubação foi baseado na analise de solo A adubação de plantio foi realizada três dias antes das mudas serem transplantadas, sendo aplicado $40 \mathrm{~kg}$ de $\mathrm{N} \mathrm{ha}^{-1}, 300 \mathrm{~kg}$ de $\mathrm{P}_{2} \mathrm{O}_{5} \mathrm{ha}^{-1}, 100 \mathrm{~kg} \mathrm{~K} \mathrm{O}_{2} \mathrm{ha}^{-}$ e 8 L.m $\mathrm{m}^{-2}$ de esterco bovino. A adubação de cobertura consistiu na aplicação de $80 \mathrm{~kg}$ de $\mathrm{N} \mathrm{ha}^{-1}$, com parcelamento aos 10, 20 e 30 dias após o transplantio, segundo o Manual de Recomendação de Calagem e Adubação para o Estado do Espírito Santo $5^{\circ}$ Aproximação.

Aos 45 dias após as mudas terem sido transplantadas quando ocorre seu desenvolvimento vegetativo máximo segundo Filgueira (2003) foi realizado corte das plantas rente ao solo e foram realizadas as avaliações das seguintes características agronômicas: número de folhas (NF); massa fresca das folhas (MFF), descartando-se as folhas externas em processo de senescência por se apresentarem sem valor comercial, o comprimento do caule $(\mathrm{CC})$, medido com régua milimetrada e massa fresca do caule (MFC). Para a pesagem, foi utilizada balança analítica de precisão. As folhas fresca foram secas em estufa de circulação forçada de ar a $70^{\circ} \mathrm{C}$ por 72 horas, para a obtenção do peso da massa seca (MSF).

Os dados foram submetidos à análise de variância e as médias foram comparadas pelo teste de Tukey ao nível de 5\% de probabilidade, utilizando o programa estatístico SAEG 9.1.

\section{RESULTADOS E DISCUSSÃO}

Em relação aos pesos de massa fresca (MFF) e seca (MSF) das folhas, não houve diferença significativa entre as cultivares Vitória de Santo Antão, Elba, Crespa Repolhuda, Lívia, Americana, Maravilha de Verão e Aurélia, apresentando estas, resultados superiores em relação a cultivar Mimosa SaladBow (Tabela 1). Esse resultado pode estar relacionado com a temperatura média do ciclo da cultura, que se encontrava favorável ao bom desenvolvimento das cultivares.

Contudo, a cultivar Mimosa SaladBow não expressou sua capacidade produtiva de massa fresca e seca, provavelmente devido a seu baixo potencial de adaptação a região de estudo, isso porque o ambiente juntamente com o componente genético são os grandes responsáveis pelas mudanças fisiológicas e morfológicas das plantas, como crescimento, floração e senescência. A ação do fotoperíodo e temperatura do ar são os fatores determinantes nas mudanças dos estádios de desenvolvimento das plantas, sendo que a temperatura do ar é o principal elemento do ambiente condicionante do desenvolvimento, interferindo tanto na emissão de folhas quanto na mudança dos estádios fenológicos (HERMES et al., 2001).

Tabela 1. Valores médios de peso de massa fresca (MFF) e seca (MSF) das folhas das cultivares de alfaces estudadas.

\begin{tabular}{lcc}
\hline Cultivares & $\begin{array}{c}\text { Massa Fresca das Folhas } \\
\left(\mathbf{g}^{-1} \text { planta }^{-1}\right.\end{array}$ & $\begin{array}{c}\text { Massa Seca das Folhas } \\
\text { (g planta }^{-1} \text { ) }\end{array}$ \\
\hline Vitória de Santo Antão & $257,6 \mathrm{~A}$ & $15,7 \mathrm{~A}$ \\
Elba & $253,2 \mathrm{~A}$ & $17,0 \mathrm{~A}$ \\
Crespa Repolhuda & $228,0 \mathrm{~A}$ & $15,5 \mathrm{~A}$ \\
Lívia & $224,4 \mathrm{~A}$ & $15,8 \mathrm{~A}$ \\
Americana & $223,6 \mathrm{~A}$ & $16,3 \mathrm{~A}$ \\
Maravilha de Verão & $216,6 \mathrm{~A}$ & $15,9 \mathrm{~A}$ \\
Aurélia & $210,0 \mathrm{~A}$ & $15,4 \mathrm{~A}$ \\
Mimosa Salad Bow & $141,8 \quad$ B & $12,3 \quad$ B \\
\hline$*$ Médias seguidas de mesma letra nas colunas não diferem entre si pelo teste de Tukey a 5\% de probabilidade. \\
\hline
\end{tabular}


Resultados semelhantes foram obtidos por Nespoliet al. (2009), onde a cultivar Elba apresentou melhores resultados, quando comparada com as demais cultivares analisadas em relação tanto a produção de massa fresca quanto ao número de folhas. Segundo Lima (2007), o peso de massa fresca comercial

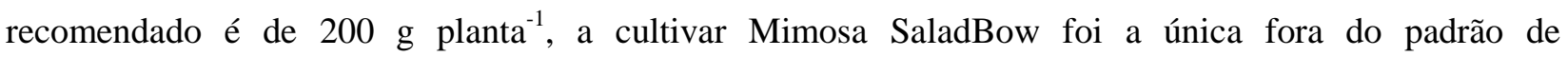
comercialização recomendado com 141,8 $\mathrm{g} \mathrm{planta}^{-1}$.

Os dados obtidos pelas cultivares Vitória de Santo Antão, Mimosa SaladBow e Aurélia foram semelhantes aos resultados obtidos por Silva et al (2007), em ensaio de cultivares de alface para cultivo nas condições edafoclimáticas do município de Rolim de Moura - RO.

A maior produção de massa fresca deve-se à própria característica botânica e hábitos de crescimento de cultivares lisas, que normalmente produzem maior número de folhas, embora nem sempre o maior número de folhas represente maior rendimento, visto que esse acontecimento dependerá das cultivares que estão sendo estudadas e comparadas e também das condições de manejo e ambientais, conforme foi constatado por Silva et al. (2008).

O peso de massa fresca do caule obtida para as cultivares Crespa Repolhuda, Lívia, Elba, Maravilha de Verão, Aurélia e Vitória de Santo Antão não diferiram estatisticamente entre si, sendo superiores aos obtidos para as cultivares Americana e Mimosa SaladBow (Tabela 2).

Tabela 2. Valores médios de massa fresca do caule (MFC) das cultivares de alfaces estudadas.

Cultivares

Crespa Repolhuda

Lívia

Elba

Maravilha de Verão

Aurélia

Vitória de Santo Antão

Americana

Mimosa Salad Bow

*Médias seguidas de mesma letra na coluna não diferem entre si pelo teste de Tukey a 5\% de probabilidade.

Resende et al. (2005) relata que no caso do caule, esse maior valor torna-se um aspecto negativo, sugerindo que a cultivar possa ter maior suscetibilidade ao pendoamento. Entretanto, apesar da importância da avaliação da massa do caule, a determinação do comprimento deste, de acordo com Luz (2009), também é relevante para indicar se uma planta de alface é mais susceptível ou não ao pendoamento.

Com relação ao comprimento do caule, as cultivares Maravilha de Verão, Crespa Repolhuda Lívia, Elba, Aurélia e Mimosa SaladBow não diferiram entre si, apresentando maior comprimento (Tabela $3)$.

Nucleus, v.9, n.2, out.2012
$24,8 \mathrm{~A}$

$24,0 \mathrm{~A}$

$22,2 \mathrm{~A}$

$22,0 \mathrm{~A}$

$21,0 \mathrm{~A}$

$10,6 \quad \mathrm{~B}$

$9,8 \quad$ B 
Tabela 3. Valores médios de comprimento do caule (CC) de cultivares de alfaces estudadas.

\section{Cultivares}

Maravilha de Verão

Crespa Repolhuda

Lívia

Elba

Aurélia

Mimosa Salad Bow

Vitória de Santo Antão

Americana
Comprimento do Caule (cm)

*Médias seguidas de mesma letra na coluna não diferem entre si pelo teste de Tukey a 5\% de probabilidade.

De acordo com Yuri (2004), o tamanho mais adequado do caule para comercialização deve-se encontrar até $6,0 \mathrm{~cm}$ de comprimento, sendo aceitáveis até $9,0 \mathrm{~cm}$ e inaceitáveis ou menos recomendados acima deste. Com isso, as cultivares avaliadas se encontram aptas para a comercialização, uma vez que, estão dentro dos limites estabelecidos para o comércio (inferior a $6,0 \mathrm{~cm}$ ) e não apresentam indícios de pendoamento. $\mathrm{O}$ florescimento prematuro encurta o período vegetativo da planta, prejudicando sua produção de folhas (YURI et al., 2005), sendo considerado um dos fatores que mais afeta o comportamento diferencial de cultivares de alface nas épocas mais quentes.

Menores comprimentos de caule são desejáveis para a alface do tipo Americana, como encontrado no presente estudo, principalmente quando destinada à indústria de beneficiamento, uma vez que proporcionam menores perdas durante o processamento. Por outro lado, o caule excessivamente comprido acarreta uma menor compactação da cabeça e dificulta o beneficiamento, afetando a qualidade final do produto (YURI et al., 2002; RESENDE et al. 2003).

Quanto ao número de folhas, observou-se que as cultivares Vitória de Santa Antão, Aurélia, Maravilha de Verão e Lívia se destacaram, apresentando um maior número de folhas, não diferindo entre si. Já as cultivares Americana, Crespa Repolhuda e Mimosa SaladBow foram as que apresentaram menor número de folhas (Tabela 4).

Tabela 4. Valores médios de número de folhas (NF) das cultivares de alfaces estudadas.

\section{Cultivares}

Vitória de Santo Antão

Aurélia

Maravilha de Verão

Lívia

Elba

Mimosa Salad Bow

Crespa Repolhuda

Americana

\section{Número de Folhas (folhas/planta)}

*Médias seguidas de mesma letra na coluna não diferem entre si pelo teste de Tukey. a 5\% de probabilidade. 
Silva et al (2006) obteve resultados semelhantes na avaliação de cultivares de alface na região de Gurupi - TO, onde a cultivar Vitória de Santo Antão destacou-se em relação ao número de folhas, produzindo uma média de 27,0 folhas/planta e as cultivares Crespa Repolhuda (16,5), Elba $(19,5)$ e Americana (14,25). Ramos et al. (2002), analisando o comportamento de cultivares de alface do grupo Crespa, encontraram resultados diferentes dos observados neste experimento, onde a cultivar Mimosa SaladBow apresentou um número médio de folhas de 21,33 e peso de matéria fresca de 222,6 g planta $^{-1}$, destacando-se em relação às demais cultivares avaliadas. A explicação para as diferenças dos resultados obtidos por Ramos et al.(2002) e os obtidos neste trabalho pode estar relacionada às diferenças de temperatura ambiente. Segundo Silva et al. (2000), a temperatura pode influenciar significativamente a cultura da alface, alterando a sua arquitetura, peso, qualidade e, principalmente, produção.

Avaliando-se conjuntamente as características peso de massa fresca das folhas e número de folhas (Tabela 1 e 4, respectivamente), as cultivares Vitória de Santo Antão e Aurélia se destacam, apresentando os melhores resultados. Analisando os valores do número de folhas conjuntamente à produção de massa fresca das folhas, pode-se observar que a cultivar Americana, que havia se destacado quanto ao peso de massa fresca, foi a que apresentou menor número de folhas.

Quanto ao tamanho do caule, a cultivar Americana apresentou um menor comprimento, o que pode ser explicado por temperaturas favoráveis ao seu desenvolvimento. Yuri (2002) relata que para ocorrer compactação das cabeças de alface seria necessário temperaturas diurnas em torno de $23^{\circ} \mathrm{C}$ e noturnas em torno de $7^{\circ} \mathrm{C}$, o que não foi verificado no presente estudo. Os resultados sugerem que a cultivar não mostrou o seu potencial de produção. Essa superioridade pode ser explicada pelas características agronômicas destas cultivares, ou seja, apresentam um grande número de folhas em relação às cultivares que não formam cabeça.

De acordo com Oliveira et al. (2004), o número de folhas por planta, juntamente com o peso da planta, é importante característica de produção, e o comprimento do caule pode ser utilizado para indicar a tolerância ao calor. Essas características seriam, as mais indicadas na seleção da cultivar para determinada região, que, juntamente com a preferência do mercado consumidor, determina a cultivar a ser utilizada.

As cultivares de alface que apresentaram maior comprimento de caule e obtiveram um menor desempenho para as demais características avaliadas (massa fresca e seca das folhas, número de folhas), pode estar relacionado a uma maior suscetibilidade das mesmas ao pendoamento precoce, devido às condições climáticas em que foram cultivadas. Com estes resultados fica evidente que as vantagens de algumas cultivares sobre outras dependem da característica considerada.

Diante dos resultados obtidos e devido ao grande número de cultivares existentes no mercado e a escassez de pesquisas na região de Alegre - ES sugere-se a realização de mais estudos com outras cultivares de alface, para determinar quais cultivares que mais se adaptam não só às condições edafoclimáticas, mas também com diferentes épocas de cultivo, haja vista que essa cultura é de grande aceitação no mercado nacional e possibilita uma grande oportunidade de diversificação e rentabilidade para o produtor .

\section{CONCLUSÃO}

1. Todas as cultivares de alfaces avaliadas apresentaram valores de comprimento de caule adequados para comercialização (inferior a $6,0 \mathrm{~cm}$ ), indicando ausência de pendoamento precoce nas mesmas.

2. Para as condições em que foi conduzido o experimento, as cultivares Vitória de Santo Antão, Crespa Repolhuda, Maravilha de Verão, Lívia, Americana, Elba e Aurélia foram mais produtivas com peso de massa fresca variando de 210,0 a 257,6 $\mathrm{g}$ planta ${ }^{-1}$. 
3. Dentre as cultivares estudadas, a cultivar Mimosa SaladBow foi a única que apresentou peso de massa fresca fora dos padrões comerciais recomendados (inferior a $200 \mathrm{~g} \mathrm{planta}^{-1}$ ).

\section{REFERÊNCIAS}

ANDREANI JUNIOR R; MARTINS D. R. Avaliação de cultivares de alface (Lactuca Sativa L.) para plantio na primavera-verão na região de Fernandópolis SP. Horticultura Brasileira, v.20, p.164-168. 2002.

CEASA - ES: Centrais de Abastecimento do Espírito Santo. Disponível em: <http://www.ceasa.es.gov.br/>. Acesso em: 01 de jun. de 2011.

COSTA, C. P.; SALA, F. C. A evolução da alface, cultura brasileira. Horticultura Brasileira, Brasília, DF, v. 23, Artigo de capa. 2005.

FIGUEIREDO et al. T. Interação genótipo x ambiente em cultivares de alface na região de Jaboticabal. Horticultura Brasileira, v.22, p.66-71, 2004.

FILGUEIRA, F.A.R. Novo Manual de olericultura - Agrotecnologia moderna na produção e comercialização de hortaliças. 2a ed. São Paulo: 412p. 2003.

HERMES et al. Emissão de folhas de alface em função da soma térmica. Revista Brasileira de Agrometeorologia, v.9, p.269-275, 2001.

LIMA, M. E. Avaliação do desempenho da cultura da alface (Lactuca sativa) cultivada em sistema orgânico de produção, sob diferentes lâminas de irrigação e coberturas do solo. 2007, 92 p.

Dissertação (Mestrado). Universidade Rural do Rio de Janeiro, Rio de Janeiro.

LUZ et al. Resistência ao pendoamento de genótipos de alface em ambientes de cultivo. Agrarian, v.2, p.71-82, 2009.

MOTA et al. Avaliação de cultivares de alface americana durante o verão em Santana da Vargem, MG. Horticultura Brasileira, v.21, no.2, 2003.

NESPOLI et al. Desempenho de cultivares de alface tipo crespa sob altas temperaturas. Horticultura Brasileira, v. 27, p.3157-3162, 2009.

OLIVEIRA et al. Divergência genética e descarte de variáveis em alface cultivada sob sistema hidropônico. Acta Scientiarum: agronomy, Maringá, v.26, p.211-217, 2004.

OLIVEIRA et al. Desempenho de cultivares de alface adubadas organicamente. Revista Verde v.2, p. 160-166, 2007.

RAMOS et al.Comportamento de cultivares de alface tipo crespa em solo e em hidroponia.2002.Disponível:<http://www.abhorticultura.com.br/biblioteca/arquivos/Download/Biblioteca /cofi1001C.pdf>. Aceso em: 19 de jun. de 2011.

RESENDE et al. Efeitos de tipos de bandejas e idade de transplantio de mudas sobre o desenvolvimento e produtividade de alface americana. Horticultura Brasileira, v.21, p.562-567, 2003.

RESENDE et al. Resposta da alface americana (Lactuca sativa 1.) a doses e épocas de aplicação de cobre. Ciência. agrotecnica., Lavras, v. 29, p. 1209-1214, nov./dez., 2005. 
SILVA GF; PEQUENO PLL; SCHIMIDT D. Avaliação de cultivares de alface (Lactuca sativa L.) nas condições edafoclimáticas do município de Rolim de Moura-RO. In: SEMINÁRIO DE PESQUISA E EXTENSÃO RURAL, 1. Anais... Rolin de Moura: UNIR. p. 1-7, 2007.

SILVA et al. Avaliação de cultivares de alface na região de Gurupi - TO. 2006.

Disponível:<http://www.abhorticultura.com.br/biblioteca/arquivos/Download/Biblioteca/46_0397.pdf>. Acesso em: 19 de jun. de 2011.

SILVA et al. Efeito da adubação foliar com Ca e B na produtividade, em cultivares de alface, produzidas em sistema hidropônico. In: $48^{\circ}$ Congresso Brasileiro de Olericultura. Anais. 2008.

SILVA et al. Comportamento de cultivares de alface em diferentes espaçamentos sob temperatura e luminosidade elevadas. Horticultura Brasileira, v. 18, p. 183-187, novembro 2000.

VIGGIANO, J. Produção de sementes de alface. In: CASTELLANE, P.D. (org.) Produção de sementes de Hortaliças. Jaboticabal: FCAV/FUNEP, 1990. p. 1-19.

YURI et al. Comportamento de cultivares de alface tipo americana em Boa Esperança. Horticultura Brasileira,v.20, p.229-232, 2002.

YURI et al. Comportamento de cultivares e linhagens de alface americana em Santana da Vargem (MG), nas condições de inverno. Horticultura Brasileira, v.22, p.322-325, 2004.

YURI et al. Comportamento de cultivares de alface americana em Santo Antônio do Amparo.

Horticultura Brasileira, Brasília, v.23, p.870-874, out-dez 2005. 